\title{
Asymmetric Division and Stem Cell Renewal without a Permanent Niche: Lessons from Lymphocytes
}

\author{
J.T. CHANG AND S.L. REINER \\ Abramson Family Cancer Research Institute and Department of Medicine, \\ University of Pennsylvania, Philadelphia, Pennsylvania 19104
}

\begin{abstract}
Numerous tissues in long-lived organisms are composed of short-lived cells. The continual regeneration of some barrier surfaces, for example, relies on adult stem cells that have the capacity to divide and produce one daughter cell destined for terminal differentiation and function and another daughter cell that renews the stem cell fate. The immune system of higher animals possesses a cellular component called lymphocytes, which face a similar need for regeneration. A lymphocyte that is recruited during an infection must give rise to cellular progeny that undergo terminal differentiation to eliminate an invading microbe, yet retain progeny that replace the recruited cell in order to maintain immunity to reinfection. Emerging evidence suggests that specifying the divergent cell fates necessary for immunity relies on the ability of the lymphocyte to exploit an evolutionarily conserved strategy for making kindred cells different-asymmetric cell division. Although the lymphocyte does not possess constitutive polarity, it appears to use a facultative interaction with another cell to nucleate unequal segregation of fate determinants relative to its plane of division. Herein, we propose that other mobile and nonadherent cells, such as blood and cancer stem cells, might exploit provisional interactions with their niche or microenvironment to achieve diversity among their daughter cells.
\end{abstract}

\section{GENERATING CELL FATE DIVERSITY, WITH OR WITHOUT A PERMANENT NICHE}

Life is a succession of cell divisions. For multicelled beings, diversity in the fate of a cell's progeny is essential for orderly tissue formation and specialized function. Knowledge of how kindred cells diverge in fate is essential for understanding organ formation and function, stem cell and tissue regeneration, immunity, and cancer. At least two distinct mechanisms, representing the cellular versions of "nature" versus "nurture," can promote daughter cell diversity (Fig. 1). After inception, identically born daughter cells can be nurtured to adopt different fates by encountering distinct signals in their environments. There also exists an evolutionarily conserved mechanism, called asymmetric cell division, whereby a dividing cell imparts unequal inheritance of its components to its two daughter cells, making them different from inception (Betschinger and Knoblich 2004; Knoblich 2008).

Scattered instances of asymmetric cell division have been described across evolution for generating specialized cells within an organ and for enabling the regeneration of progenitor cells in tissues that require continuous production of differentiated progeny, such as skin (Lechler and Fuchs 2005). Asymmetric cell division has typically been associated with tissues that already possess intrinsic apical-basal polarity. In those situations, the constitutive attachment of a cell to the basement membrane provides a framework that allows the daughter attached to the basement membrane to retain the stem cell fate,

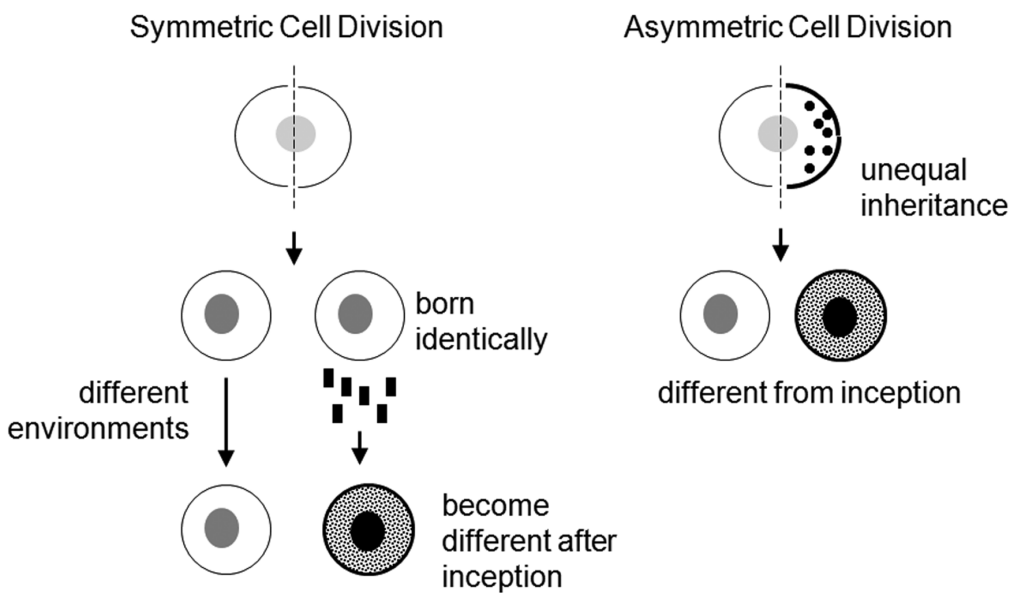

Figure 1. Alternative mechanisms for generating cell-fate diversity. (Left) Two identically born daughter cells encounter a disparity in their extrinsic signaling (black rectangles), resulting in their subsequent adoption of distinct cell fates. (Right) A cell is signaled in such a way that it organizes asymmetric localization of a determinant (black circles) relative to the plane of division. The two daughters receive an unequal share of the determinant, making them different from inception. 
whereas the daughter that detaches initiates the process of terminal differentiation.

Not all stem cells, however, possess a constitutive niche. Nonadherent or migratory cells such as blood stem cells and metastatic cancer-initiating cells are motile and may have only facultative encounters with their niche or microenvironment. We have recently begun to explore the possibility that extrinsic signaling emanating from a point on a cell's surface could act as a guiding principle to orient the machinery necessary for the execution of cell division and simultaneously reorganize the preformed components of the cell (Chang et al. 2007). The coordination of these events could enable a dividing cell whose external surface may have only provisionally communicated with the microenvironment or niche to create two daughter cells that are different from inception. Such a mechanism may offer a solution to a long-standing puzzle of vertebrate immunity and provide a framework to study how self-renewal or specialization is achieved in other mobile cells.

\section{REGENERATING LYMPHOCYTES FOR IMMUNITY}

Most of the mature blood lineages, red or white, have a finite and relatively short life span. Attrition of these lineages during homeostasis is continually offset by the production and subsequent maturation of lineage-committed progenitors from a blood stem cell. Each of the mature blood lineages is postmitotic and does not proliferate in response to stress. The need for excess numbers to respond to acute changes (hemorrhage or infection) is accommodated by mobilization and differentiation from progenitors and sequestration or migration to inflamed sites.

The most recent evolutionary addition to the immune armamentarium of vertebrates is a set of cells called lymphocytes. The major lineages of lymphocytes are B cells, the producers of antibodies, and $\mathrm{CD}^{+}$and $\mathrm{CD} 8^{+} \mathrm{T}$ lymphocytes. $\mathrm{CD}^{+} \mathrm{T}$ cells orchestrate the selection of the type of defense mechanisms that are appropriate to fend off the different classes of microbial pathogens (Reiner 2007; Reiner et al. 2007). $\mathrm{CD}^{+} \mathrm{T}$ cells participate in the defense against intracellular microbes, viruses, and tumors by killing target cells with cytolytic granules and secreting cytokines that activate intracellular microbicides. Successful habitation of a microbe-filled planet is dependent on the lymphocyte system of defense that arose late in evolution in an ancestor of jawed fish. Lack of normal gene products that are required for lymphocyte development results in a severe combined immunodeficiency (SCID) phenotype.

The way lymphocytes recognize foreign intruders is different from that of all other types of white blood cells. All other mature white blood cells are clonally identical among their lineage with regard to the receptors that bind foreign ligands. The lymphocyte system of recognition, however, is predicated on an unprecedented diversity of recognition. The foreign ligand-binding proteins (antigen receptor) of each lymphocyte within a given lineage are clonally distinct or bar-coded from one another (Chang and Reiner 2007). During lymphocyte development, random somatic recombination occurs at the multiple poly- morphic gene segments encoding the potential antigen receptor polypeptides. After its acquisition of a unique antigen receptor and successful screening to ensure that it will not be overtly self-destructive to the host, which occurs in specialized developmental sites (bone marrow and thymus), a nascent lymphocyte is exported to the peripheral lymphoid tissues for circulation through lymph nodes, spleen, and blood. This army of lymphocytes carries such tremendous diversity in antigen recognition that it is now likely that the host could be infected with virtually any microbe and mount a specific response against it.

Lymphocytes that have not yet encountered their foreign antigen are called naïve T cells and B cells. Naïve lymphocytes are highly motile and are continually patrolling peripheral lymphoid tissues for evidence of microbial invasion. Although they do not divide during their surveillance, they have a much longer life span than that of the other blood cells, many months if not a year. During an immune response to pathogen, a naïve $\mathrm{T}$ cell patrolling peripheral lymphoid tissues encounters an antigen-presenting cell displaying microbial components on its surface (Reiner 2007; Reiner et al. 2007). Because of its sheer rarity in recognizing the microbial invader, the lymphocyte faces the challenge of producing large numbers of terminally differentiated progeny needed for acute defense (called effector cells). Whereas other blood lineages are postmitotic, naïve lymphocytes indeed have the capacity to undergo massive clonal expansion in response to the antigen trigger in order to accommodate the need for large numbers of effector cells to match the microbial burden. The progeny of a naïve lymphocyte undergoing massive cellular expansion are also empowered with new programs of gene expression that make them effective as an effector cell (Bird et al. 1998; Reiner 2007; Reiner et al. 2007). Antigen-experienced $\mathrm{T}$ cells heritably remodel chromatin at genes encoding cytokines and cytolytic materials. The progeny of the naïve cell that have undergone transit amplification and effector cell differentiation leave the lymph node and migrate to the tissue site of microbial invasion. Upon encounter with pathogen in skin or lung, these effector cells now release their cytokines or destructive granules at target cells harboring intracellular infection or those cells displaying evidence of pathogen interaction.

In contrast to other white blood cells, replenishment of a useful naïve lymphocyte cannot be derived from a blood stem cell because it is impossible for the blood stem cell to specify that the correct antigen receptor would eventually be expressed (Chang and Reiner 2007). The effector cell progeny of a naïve lymphocyte that migrate from lymph node to peripheral tissues to do battle with the invading microbe are themselves now postmitotic, terminally differentiated, and short-lived. If all progeny of a naïve lymphocyte underwent terminal differentiation into short-lived effector cells, it might be expected that the host would be left with a gaping hole in its defense because the first encounter has consumed or depleted the cells specific for this microbe. Centuries of experience, however, have taught that subsequent encounters with a microbe are rarely met by ignorance or an unresponsive state. Instead, subsequent encounters with a given microbe are often heralded with a faster and stronger lym- 
phocyte response than the first battle, a phenomenon known as immunity. This is thought to be possible owing to the ability of some antigen-experienced progeny of the naïve lymphocyte to undergo a program of regeneration and self-renewal (so-called memory cells).

\section{ASYMMETRIC CELL DIVISION AS A POTENTIAL SOLUTION FOR THE PARADOX OF IMMUNITY}

How does a thin layer of defense repair itself when punctured, leaving behind a thicker segment of armor instead of a gaping hole? In other words, how does a naïve $\mathrm{T}$ cell accommodate the mutually exclusive needs for terminally differentiated effector cells and self-renewing memory cells? One potential solution to this conundrum is for the lymphocyte to use a mechanism that is a frequent solution for accommodating lifelong function in longlived beings possessing short-lived cells. The adult somatic stem cell is a paradigm for tissue regeneration (Morrison and Kimble 2006; Knoblich 2008). In skin, for example, a stem cell residing in the basement membrane can periodically divide asymmetrically, producing one daughter that is amplified and growing apically to eventually give rise to the mature tegument and another daughter that retains its attachment to the basal surface and maintains the identity of the original stem cell (Lechler and Fuchs 2005). In this way, the stem cell uses asymmetric division to continually regenerate cells destined for acute function and cells that maintain the lineage over a lifetime.

Is it possible for nonadherent cells, such as members of the blood lineages that lack constitutive attachment and apparent polarity, to undergo an asymmetric division? We began to entertain the possibility that lymphocytes might exploit the principle of asymmetric cell division in order to achieve essential heterogeneity in the fates of daughter cells (Chang et al. 2007). Our hypothesis arose because of ample literature describing facultative polarity in interphase $\mathrm{T}$ cells undergoing stimulation by antigen (Monks et al. 1998; Huppa and Davis 2003; Lin et al. 2005; Cemerski and Shaw 2006). The hypothesis became further embellished based on in vivo time-lapse imaging, documenting an unusually prolonged contact between the naïve $\mathrm{T}$ cell and the cell that is decorated with foreign antigen before the T cell's first division (Miller et al. 2002; Stoll et al. 2002; Bousso and Robey 2003; Mempel et al. 2004).

\section{LYMPHOCYTES ESTABLISH FACULTATIVE POLARITY BEFORE MITOSIS}

When a T cell (naïve, effector, or memory) is engaged by an antigen-presenting cell, ligation of the antigen receptor propagates a signal transduction cascade that rapidly activates or represses the transcription of multiple genes. It is also recognized that antigen-receptor-induced signals do not solely transmit information to the nucleus. In particular, antigen receptor signaling, probably in cooperation with T-cell integrin signaling, results in the coalescence of signaling and adhesive components at the site of contact between the $\mathrm{T}$ cell and antigen-presenting cell. This structure, termed the immunological synapse, is composed of an inner confluence of antigen receptor and associated polypeptides encircled by an outer ring composed of an adhesive integrin receptor (Monks et al. 1998). Other components of the immunological synapse include the receptors for certain cytokines, such as interferon- $\gamma($ IFN- $\gamma$ ) and interleukin-2 (IL-2), as well as cytoplasmic signaling intermediates associated with the antigen receptor (Monks et al. 1998; Maldonado et al. 2004).

The formation of the immunological synapse is accompanied by a substantial reorganization of several cellular components. The microtubule-organizing center and Golgi apparatus move to a site just below the immunological synapse. Recruitment of mitochondria to the synapse has been suggested to regulate local concentrations of calcium and allow its influx across plasma membrane channels, which is needed to activate signaling components (Quintana et al. 2007). Signaling through the $\mathrm{T}$-cell antigen receptor also communicates with an evolutionarily conserved network of proteins with roles in coordinating polarity and asymmetric cell division (Betschinger and Knoblich 2004; Knoblich 2008). In lymphocytes, the partitioning-defective (PAR) proteins appear to be reorganized both during migration and following antigen receptor signaling (Ludford-Menting et al. 2005). A mammalian homolog of atypical protein kinase $\mathrm{C}$ (aPKC), an essential component of a complex containing the PAR proteins Par- 3 and Par- 6 , has further been implicated in T-cell function (Ludford-Menting et al. 2005; Martin et al. 2005; Real et al. 2007). A role for two other conserved polarity proteins, Scribble (Scrib) and discs large (Dlg), has also been suggested during T-cell activation and migration (Xavier et al. 2004; LudfordMenting et al. 2005; Round et al. 2005; Stephenson et al. 2007).

The initial descriptions of the immunological synapse were made in effector $\mathrm{T}$ cells, and its formation was understood as an adaptive mechanism to ensure that cytokine and cytolytic granules could be directed judiciously to the site of intercellular communication with a target cell (Huse et al. 2006; Stinchcombe et al. 2006). Although such facultative polarity has also been observed in naïve $\mathrm{T}$ cells, the reasons for such behavior remained controversial and ambiguous. As the field began to image the dynamics of intercellular communication between the naïve $\mathrm{T}$ cell and its antigen-presenting cell in vivo, it became tempting to hypothesize that the facultative polarity of naïve cells could serve a purpose different from that of effector cells, wherein it literally guides the execution of their acute function. Intravital, time-lapse imaging of a naïve $\mathrm{T}$ cell during its first day of the immune response indicated that the $\mathrm{T}$ cell forms a prolonged conjugate with its antigen-presenting cell that lasts until the first T-cell division (Miller et al. 2002; Stoll et al. 2002; Bousso and Robey 2003; Mempel et al. 2004). We therefore hypothesized that synapse-like polarity in a naïve cell might not be forming solely to instruct the acute behavior of the interphase lymphocyte, but rather to establish an organization of cellular components in the mitotic cell preparing for its first division (Fig. 2). 

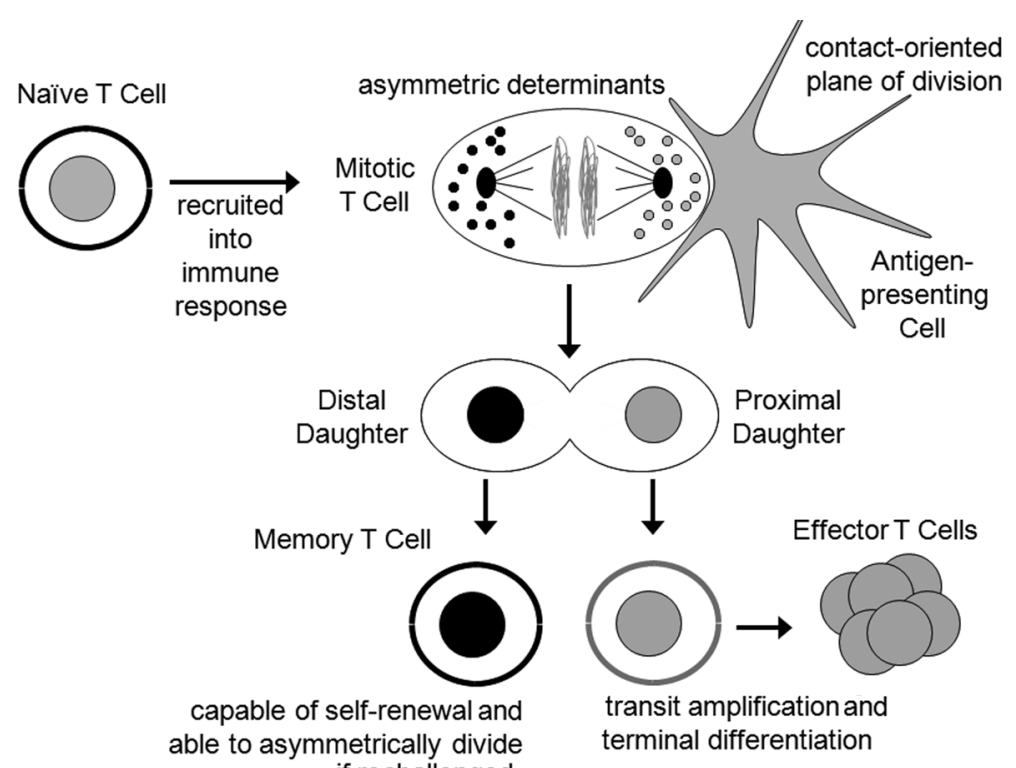

Figure 2. Asymmetric cell division initiating the immune response. A migrating naïve $\mathrm{T}$ cell is recruited into the immune response when its unique antigen receptor recognizes microbial components presented by an antigen-presenting cell in the draining lymph node. The activation induced by antigen receptor ligation results in facultative polarity of the lymphocyte. The provisional but prolonged interaction between the $\mathrm{T}$ cell and antigen-presenting cell lasts until mitosis. The contact surface allows the $\mathrm{T}$ cell to orient its plane of division as well as to segregate asymmetric determinants relative to the plane of division. The proximal daughter undergoes vigorous proliferation and terminal differentiation to create terminally differentiated effector cells that leave the lymph node to perform acute function at the barrier surfaces where pathogens invade. The distal daughter differentiates into a memory cell, which serves as the long-term replacement of this antigen-specific clone. The stem-cell-like memory cell is capable of self-renewal by slowly dividing symmetrically in the absence of recurrent infection. In the face of reinfection, the newly activated memory cell would be capable of asymmetrically dividing to produce more effector cell progeny from its proximal daughter as well as a distal daughter that would renew the memory cell.

\section{ASYMMETRIC DIVISION OF CLONALLY SELECTED T CELLS}

Examination of a naïve $\mathrm{T}$ lymphocyte responding to a pathogen suggested that it indeed exploits contact with its antigen-presenting cell as a provisional surface on which to organize polarity and subsequent asymmetric division (Chang et al. 2007). Interphase T-cell blasts were found to contain synapse-like organization during the in vivo immune response. This morphology persisted into mitosis and it was contingent on prolonged contact between the $\mathrm{T}$ cell and antigen-presenting cell (Fig. 2). One centrosome remains proximal to the contact, whereas the other is positioned at the distal pole of the mitotic T-cell blast. In so doing, the plane of division of the $\mathrm{T}$ cell is oriented parallel to the site of contact. In addition, key components are segregated to one or the other side of the impending plane of division. Several classes of proteins appear to be asymmetrically distributed in this manner, including immune receptors, signaling molecules, polarity proteins, and potential fate determinants. We also observed complementary localization of members of the aPKC-Par3-Par6 complex distally and the Scrib-Dlg-Lgl family of polarity proteins proximally, which was evident in both interphase and mitotic lymphocyte blasts (Chang et al. 2007).

As naïve $\mathrm{T}$ cells underwent their initial cytokinesis, the incipient daughters inherited unequal shares of several of these proteins, which was also contingent on prolonged contact with the antigen-presenting cell (Chang et al.
2007). Phenotypic and functional analyses indicated that the daughter "proximal" to the provisional contact with the antigen-presenting cell undergoes transit amplification and terminal differentiation as an effector cell, whereas the daughter "distal" to the contact site eventually gives rise to a self-renewing memory cell (Fig. 2).

In a sense, neither of the first two daughter lymphocytes is identical to the original naïve mother cell. The terminally differentiated effector branch (proximal daughter) appears to be destined for acute function, whereas the selfrenewing memory branch (distal daughter) carries a distinctive marking of its lack of naïveté and is also empowered with a capacity for slow proliferative turnover in the absence of antigen to offset the attrition of a finite life span. The self-renewing memory lineage, however, does appear to accomplish the fundamental need of barcoded lymphocytes for a system of intrinsic regeneration: These memory cells retain the same anatomic and migratory behavior of the original naive lymphocyte, patrolling peripheral lymphoid tissue in anticipation of a recurrent invasion by the microbe that their naïve progenitor was suited to recognize. Indeed, preliminary studies suggest that these memory cells are stem-cell-like, able to maintain their numbers by periodic division in the absence of the threat and to undergo conservative, asymmetric division in the face of reinvasion by their microbial nemesis (Fig. 2). In the case of reinfection, memory cells appear to yield proximal daughters that undergo transit amplification and terminal differentiation to effector cells, whereas the distal 
daughters appears to retain the identity of the parental memory cell.

It might be considered unusual for the daughter proximal to the contact with the antigen-presenting cell to abandon the conservative role of replacing the mother cell while the distal daughter becomes the long-term replacement for the selected naïve clone. In typical stem cell arrangements, the daughter cell closer to the niche retains the mother cell's less-differentiated identity, whereas the distal daughter cell is liberated to undergo terminal differentiation (Morrison and Kimble 2006; Knoblich 2008). It is possible that the explanation for the apparent upsidedown behavior of the $\mathrm{T}$ cell is that the antigen-presenting cell is not really a niche but is instead an "anti-niche." The pathogen-associated antigen-presenting cell has been induced to provide signals that are necessary to initiate rapid cell division and terminal effector differentiation of lymphocytes. Proximity to the differentiative information is thus likely to specify greater change, whereas arising from the distal pole is more likely to foster the less-differentiated state of the memory cell.

\section{ASYMMETRIC CELL DIVISION IN OTHER BLOOD LINEAGES AND CANCER?}

That the process of asymmetric T-cell division involves a core set of evolutionarily conserved regulators of cell polarity raises the possibility that other lymphocytes having provisional contacts may also be capable of exploiting this strategy to generate cell-fate diversity. Selected CD $4^{+}$ $\mathrm{T}$ cells give rise to daughter cell fates that have differing roles in the host defense, suggesting the possibility that asymmetric cell division can create diversity among effector cells in addition to enabling terminal differentiation versus self-renewal (Reiner 2007; Reiner et al. 2007). A potential mechanism for more than two branches in the fate map of a lymphocyte is suggested by the findings that the daughter cells of a naïve $\mathrm{T}$ cell may also partake in cell-to-cell communication with antigen-presenting cells (Celli et al. 2005; Obst et al. 2005).

Like T lymphocytes, B lymphocytes divide and diversify their fates upon encountering pathogen. The progeny of a selected naïve B cell undergo further somatic recombination to generate antibody molecules that have selective functions in defense against microbes. In addition, an activated naïve B lymphocyte must give rise to terminally differentiated, antibody-producing plasma cells as well as self-renewing memory cells. During pathogen invasion, B cells migrate within a lymph node to an area where they can interact with helper T cells. Such interactions precede B-cell division, raising the possibility that B cells could exploit their interaction with helper $\mathrm{T}$ cells as a provisional surface on which to organize polarity and subsequent asymmetric divisions.

Seminal experiments performed in the 1950s and 1960s demonstrated that a single hematopoietic stem cell has the capacity to reconstitute all of the terminally differentiated, mature blood lineages while still yielding progeny with an undifferentiated fate (Becker et al. 1963). This is compatible with the hypothesis that hematopoietic stem cells might undergo conservative cell divisions, produc- ing one differentiating progeny and one undifferentiated, self-renewing progeny. It has remained unclear, however, whether hematopoietic stem cells accomplish asymmetric cell division and, if so, how.

Hematopoietic stem cells within the bone marrow have been observed in close proximity to stromal cells, osteoblasts, and endothelial cells of blood vessels (Kiel et al. 2005). These observations have led to the hypothesis that one or more of these cells might constitute the stem cell niche in the bone marrow. Contact with the niche could direct orientation of the mitotic spindle of a hematopoietic stem cell in such a way that the daughter cell remaining attached to the niche would retain the ability to self-renew, whereas the daughter dividing away from the niche would undergo terminal differentiation. Other cells lining the bone marrow cavity could also serve to direct asymmetric cell division in later branches of the differentiating progeny in order to parse two distinct lineage branches from a common progenitor. Improvements in time-lapse intravital imaging will be of great value in determining whether any of these hypothetical scenarios are operative (Sipkins et al. 2005).

One of the fundamental questions of cancer biology relates to the mechanism by which tumors are able to maintain themselves. One possibility is that each cell within a tumor has the capacity to maintain itself. Alternatively, it is possible that self-renewal properties might be a characteristic of a small fraction of cells within the tumor, so-called cancer stem cells (Wang and Dick 2005). How might cancer stem cells self-renew? The tumor microenvironment, including stromal cells and extracellular matrix proteins, is thought to have a profound influence on cancer development (Bissell and Labarge 2005; Engler et al. 2006; Karnoub et al. 2007). It is therefore tempting to speculate that the tumor microenvironment might promote the self-renewal of cancer stem cells by serving as the provisional surface to organize cellular components that might enable asymmetric cell division.

\section{A UNIFYING MODEL FOR CELL-FATE DIVERSITY IN MULTICELLULAR LIFE}

Signal transduction is frequently considered to result in information transfer to the nucleus, reprogramming the gene expression profile needed to specify a given cell fate. During development, immunity, or cancerous growth, cell fate may not always be adopted or at least finalized until after a cell has divided. In some settings, the progeny of a cell, rather than the original cell that received the signal, must alter their gene expression profile. It is known that signaling can also communicate to the preformed components of the cell within the cytoplasm, resulting in spatial reorganization that can direct the cytoskeleton and other elements that may impact a cell that is preparing to divide.

Although we have recently provided evidence that an antigen-presenting cell might provide a provisional surface for lymphocytes to organize polarity and asymmetric cell division, it is also possible that other cell types, and even noncellular surfaces, such as extracellular matrix protein, could serve the same function (Fig. 3). In this 


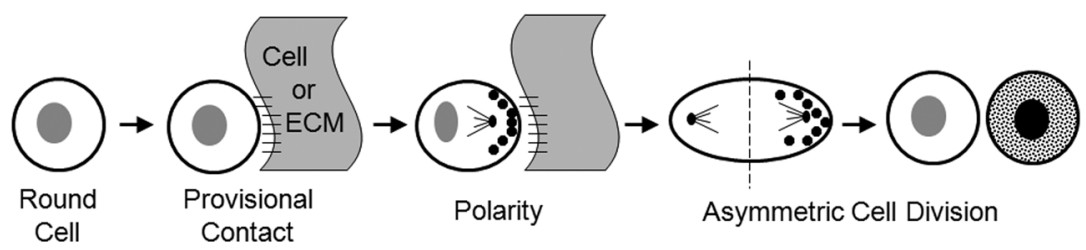

Figure 3. A unifying model of asymmetric division in multicelled life. A cell may encounter a provisional interaction with some cellular surface or extracellular matrix (ECM) that may transduce a signal to its nucleus but also organize polarity in its cytoplasmic contents and its machinery that execute cell division. If the cell is preparing for division, this could lead to unequal information transfer to its daughter cells. It is speculated that such provisional polarity may explain how mobile cells (lymphocytes, blood stem cells, metastatic cancer stem cells) achieve asymmetric cell division in the absence of a constitutive niche.

way, cells that do not exist in a conventionally stratified apical-basal tissue could have provisional communications before they divide to coordinate cell polarity and subcellular segregation. By signaling to cellular components other than the nucleus, information transfer to daughter cells can thus be rendered unequal. Some wellcharacterized examples of asymmetric cell division have been described in varied aspects of multicellular life. It now remains to be determined how frequently in life a signal delivered to a point on a cell that is preparing to divide may actually result in an asymmetric cell division.

\section{ACKNOWLEDGMENTS}

The authors are grateful to members of the Reiner laboratory for helpful discussion, Jiyeon Kim for critical suggestions, and the National Institutes of Health, Abramson Family, the American Gastroenterological Association, and Howard Hughes Medical Institute for financial support.

\section{REFERENCES}

Becker, A.J., McCulloch, E.A., and Till, J.E. 1963. Cytological demonstration of the clonal nature of spleen colonies derived from transplanted mouse marrow cells. Nature 197: 452-454.

Betschinger, J. and Knoblich, J.A. 2004. Dare to be different: Asymmetric cell division in Drosophila, C. elegans and vertebrates. Curr. Biol. 14: R674-R685.

Bird, J.J., Brown, D.R., Mullen, A.C., Moskowitz, N.H., Mahowald, M.A., Sider, J.R., Gajewski, T.F., Wang, C.R., and Reiner, S.L. 1998. Helper T cell differentiation is controlled by the cell cycle. Immunity 9: 229-237.

Bissell, M.J. and Labarge, M.A. 2005. Context, tissue plasticity, and cancer: Are tumor stem cells also regulated by the microenvironment? Cancer Cell 7: 17-23.

Bousso, P. and Robey, E. 2003. Dynamics of CD8 ${ }^{+}$T cell priming by dendritic cells in intact lymph nodes. Nat. Immunol. 4: 579-585.

Celli, S., Garcia, Z., and Bousso, P. 2005. CD4 T cells integrate signals delivered during successive DC encounters in vivo. $J$. Exp. Med. 202: 1271-1278.

Cemerski, S. and Shaw, A. 2006. Immune synapses in T-cell activation. Curr. Opin. Immunol. 18: 298-304.

Chang, J.T. and Reiner, S.L. 2007. Protection one cell thick. Immunity 27: 832-834.

Chang, J.T., Palanivel, V.R., Kinjyo, I., Schambach, F., Intlekofer, A.M., Banerjee, A., Longworth, S.A., Vinup, K.E., Mrass, P., Oliaro, J., et al. 2007. Asymmetric T lymphocyte division in the initiation of adaptive immune responses. Science 315: 1687-1691.

Engler, A.J., Sen, S., Sweeney, H.L., and Discher, D.E. 2006. Matrix elasticity directs stem cell lineage specification. Cell 126: 677-689.
Huppa, J.B. and Davis, M.M. 2003. T-cell-antigen recognition and the immunological synapse. Nat. Rev. Immunol. 3: 973-983.

Huse, M., Lillemeier, B.F., Kuhns, M.S., Chen, D.S., and Davis, M.M. 2006. T cells use two directionally distinct pathways for cytokine secretion. Nat. Immunol. 7: 247-255.

Karnoub, A.E., Dash, A.B., Vo, A.P., Sullivan, A., Brooks, M.W., Bell, G.W., Richardson, A.L., Polyak, K., Tubo, R., and Weinberg, R.A. 2007. Mesenchymal stem cells within tumour stroma promote breast cancer metastasis. Nature 449: 557-563.

Kiel, M.J., Yilmaz, O.H., Iwashita, T., Yilmaz, O.H., Terhorst, C., and Morrison, S.J. 2005. SLAM family receptors distinguish hematopoietic stem and progenitor cells and reveal endothelial niches for stem cells. Cell 121: 1109-1121.

Knoblich, J.A. 2008. Mechanisms of asymmetric stem cell division. Cell 132: 583-597.

Lechler, T. and Fuchs, E. 2005. Asymmetric cell divisions promote stratification and differentiation of mammalian skin. Nature 437: 275-280.

Lin, J., Miller, M.J., and Shaw, A.S. 2005. The c-SMAC: Sorting it all out (or in). J. Cell Biol. 170: 177-182.

Ludford-Menting, M.J., Oliaro, J., Sacirbegovic, F., Cheah, E.T., Pedersen, N., Thomas, S.J., Pasam, A., Iazzolino, R., Dow, L.E., Waterhouse, N.J., et al. 2005. A network of PDZcontaining proteins regulates $T$ cell polarity and morphology during migration and immunological synapse formation. Immunity 22: 737-748.

Maldonado, R.A., Irvine, D.J., Schreiber, R., and Glimcher, L.H. 2004. A role for the immunological synapse in lineage commitment of CD4 lymphocytes. Nature 431: 527-532.

Martin, P., Villares, R., Rodriguez-Mascarenhas, S., Zaballos, A., Leitges, M., Kovac, J., Sizing, I., Rennert, P., Marquez, G., Martinez, A.C., Diaz-Meco, M.T., and Moscat, J. 2005. Control of T helper 2 cell function and allergic airway inflammation by PKCל. Proc. Natl. Acad. Sci. 102: 9866-9871.

Mempel, T.R., Henrickson, S.E., and Von Andrian, U.H. 2004. T-cell priming by dendritic cells in lymph nodes occurs in three distinct phases. Nature 427: 154-159.

Miller, M.J., Wei, S.H., Parker, I., and Cahalan, M.D. 2002. Two-photon imaging of lymphocyte motility and antigen response in intact lymph node. Science 296: 1869-1873.

Monks, C.R., Freiberg, B.A., Kupfer, H., Sciaky, N., and Kupfer, A. 1998. Three-dimensional segregation of supramolecular activation clusters in T cells. Nature 395: 82-86.

Morrison, S.J. and Kimble, J. 2006. Asymmetric and symmetric stem-cell divisions in development and cancer. Nature 441: 1068-1074.

Obst, R., van Santen, H.M., Mathis, D., and Benoist, C. 2005. Antigen persistence is required throughout the expansion phase of a CD4 ${ }^{+} \mathrm{T}$ cell response. J. Exp. Med. 201: 1555-1565.

Quintana, A., Schwindling, C., Wenning, A.S., Becherer, U., Rettig, J., Schwarz, E.C., and Hoth, M. 2007. T cell activation requires mitochondrial translocation to the immunological synapse. Proc. Natl. Acad. Sci. 104: 14418-14423.

Real, E., Faure, S., Donnadieu, E., and Delon, J. 2007. Cutting edge: Atypical PKCs regulate T lymphocyte polarity and scanning behavior. J. Immunol. 179: 5649-5652.

Reiner, S.L. 2007. Development in motion: Helper T cells at 


\section{A STEM CELL MODEL OF IMMUNITY}

work. Cell 129: 33-36.

Reiner, S.L., Sallusto, F., and Lanzavecchia, A. 2007. Division of labor with a workforce of one: Challenges in specifying effector and memory T cell fate. Science 317: 622-625.

Round, J.L., Tomassian, T., Zhang, M., Patel, V., Schoenberger, S.P., and Miceli, M.C. 2005. Dlgh1 coordinates actin polymerization, synaptic $\mathrm{T}$ cell receptor and lipid raft aggregation, and effector function in T cells. J. Exp. Med. 201: 419-430.

Sipkins, D.A., Wei, X., Wu, J.W., Runnels, J.M., Cote, D., Means, T.K., Luster, A.D., Scadden, D.T., and Lin, C.P. 2005. In vivo imaging of specialized bone marrow endothelial microdomains for tumour engraftment. Nature 435: 969-973. Stephenson, L.M., Sammut, B., Graham, D.B., Chan-Wang, J., Brim, K.L., Huett, A.S., Miletic, A.V., Kloeppel, T., Landry, A., Xavier, R., and Swat, W. 2007. DLGH1 is a negative reg- ulator of T lymphocyte proliferation. Mol. Cell. Biol. 27: 7574-7581.

Stinchcombe, J.C., Majorovits, E., Bossi, G., Fuller, S., and Griffiths, G.M. 2006. Centrosome polarization delivers secretory granules to the immunological synapse. Nature 443: 462-465.

Stoll, S., Delon, J., Brotz, T.M., and Germain, R.N. 2002. Dynamic imaging of $\mathrm{T}$ cell-dendritic cell interactions in lymph nodes. Science 296: 1873-1876.

Wang, J.C. and Dick, J.E. 2005. Cancer stem cells: Lessons from leukemia. Trends Cell Biol. 15: 494-501.

Xavier, R., Rabizadeh, S., Ishiguro, K., Andre, N., Ortiz, J.B., Wachtel, H., Morris, D.G., Lopez-Ilasaca, M., Shaw, A.C., Swat, W., and Seed, B. 2004. Discs large (Dlg1) complexes in lymphocyte activation. J. Cell Biol. 166: 173-178. 


\section{$8_{\mathrm{CSH}}^{\infty}$ Cold Spring Harbor Symposia SYMPOSIA}

\section{Asymmetric Division and Stem Cell Renewal without a Permanent Niche: Lessons from Lymphocytes}

J.T. Chang and S.L. Reiner

Cold Spring Harb Symp Quant Biol 2008 73: 73-79 originally published online November 6, 2008 Access the most recent version at doi:10.1101/sqb.2008.73.008

References This article cites 36 articles, 13 of which can be accessed free at: http://symposium.cshlp.org/content/73/73.full.html\#ref-list-1

License

Email Alerting Receive free email alerts when new articles cite this article - sign up in the Service box at the top right corner of the article or click here.

To subscribe to Cold Spring Harbor Symposia on Quantitative Biology go to: http://symposium.cshlp.org/subscriptions 